\title{
Exploring personality traits, mindfulness and sense of coherence of women working in higher education
}

\begin{tabular}{|c|c|}
\hline \multicolumn{2}{|c|}{$\begin{array}{l}\text { Authors: } \\
\text { Claude-Hélène Mayer }^{1} \text { (D) } \\
\text { Sabie Surtee }^{2} \text { (D) } \\
\text { Delene Visser }^{1}\end{array}$} \\
\hline \multicolumn{2}{|c|}{$\begin{array}{l}\text { Affiliations: } \\
{ }^{1} \text { Department of Industrial } \\
\text { and Organisational } \\
\text { Psychology, University of } \\
\text { South Africa, South Africa }\end{array}$} \\
\hline \multicolumn{2}{|c|}{$\begin{array}{l}{ }^{2} \text { Higher Education Resource } \\
\text { Services Network in } \\
\text { South Africa, Cape Town, } \\
\text { South Africa }\end{array}$} \\
\hline \multicolumn{2}{|c|}{$\begin{array}{l}\text { Corresponding author: } \\
\text { Claude-Hélène Mayer, } \\
\text { claudemayer@gmx.net }\end{array}$} \\
\hline \multicolumn{2}{|c|}{$\begin{array}{l}\text { Dates: } \\
\text { Received: } 15 \text { Nov. } 2014 \\
\text { Accepted: } 08 \text { Apr. } 2016 \\
\text { Published: } 22 \text { July } 2016\end{array}$} \\
\hline \multicolumn{2}{|c|}{$\begin{array}{l}\text { How to cite this article: } \\
\text { Mayer, C-H., Surtee, S., \& } \\
\text { Visser, D. (2016). Exploring } \\
\text { personality traits, } \\
\text { mindfulness and sense of } \\
\text { coherence of women working } \\
\text { in higher education. SA } \\
\text { Journal of Human Resource } \\
\text { Management/SA Tydskrif vir } \\
\text { Menslikehulpbronbestuur, } \\
\text { 14(1), a674. http://dx.doi. } \\
\text { org/10.4102/sajhrm. } \\
\text { v14i1.674 }\end{array}$} \\
\hline \multicolumn{2}{|c|}{$\begin{array}{l}\text { Copyright: } \\
\text { (C) 2016. The Authors } \\
\text { Licensee: AOSIS. This } \\
\text { is licensed under the } \\
\text { Creative Commons } \\
\text { Attribution License. }\end{array}$} \\
\hline \multicolumn{2}{|l|}{ Read online: } \\
\hline 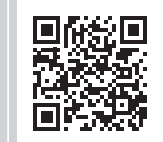 & $\begin{array}{l}\text { Scan this QR } \\
\text { code with your } \\
\text { smart phone or } \\
\text { mobile device } \\
\text { to read online. }\end{array}$ \\
\hline
\end{tabular}

Orientation: Previous research shows that personality traits (PT), mindfulness (MI) and sense of coherence (SOC) are connected to psychological well-being and of importance to Human Resource Management (HRM).

Purpose: The purpose of this article was to determine the relationship between PT, MI and SOC of women working in South African Higher Education Institutions (HEIs).

Motivation for study: The study explores the relationships of PT, MI and SOC in women in HEIs to contribute to a deeper understanding of these relationships within the HRM context, particularly with regard to training and development in HEIs.

Research design, approach and method: A cross-sectional, survey-based research design was used to address the research objective. Both snowball and convenience sampling were utilised to obtain the sample $(n=125)$. The sample was derived from the Higher Education Resource Services network. The Life Orientation Questionnaire, Freiburger MI Inventory and Big Five PT Questionnaire were utilised and showed acceptable levels of reliability. Exploratory factor analysis with either a direct oblimin or varimax rotation was used to investigate the factor structure of the questionnaires ( $\lambda<1$ were used), because one of the questionnaires had not been used in the South African context before. Descriptive statistics, factor analysis, Spearman/ Pearson correlations, canonical correlations and multiple regressions were used to determine the relationship between the variables.

Main findings: The results showed a significant relationship between the components PT, MI and SOC. It appears that PT plays a significant role in influencing MI and SOC.

Practical/managerial implications: Managers and human resource practitioners need to recognise how PT, MI and SOC interrelate and need to become aware of the impact of these positive psychological constructs on women in HEIs.

Contribution: These findings contribute new knowledge that can be used to create healthy HEIs through empirically-based, gender-specific training programmes.

\section{Introduction}

Research in higher education institutions (HEIs) has emphasised that African institutions face managerial and social inequities, such as gender imbalances (Teferra \& Altback, 2004), gender discrimination, stereotypes and bias (Martin \& Barnard, 2013). These factors negatively influence the self-perceived psychological well-being of women (Mayer \& Van Zyl, 2013) and affect their ability to cope with life/work-related demands (Mostert, 2009). Latzman and Masuda (2013) suggested that certain personality 'traits' may act as a buffer against the onset of psychopathology associated with the aforementioned demands. Yet, Human Resource Management (HRM) research on psychological well-being, sense of coherence (SOC) and mindfulness (MI), as well as the buffering personality traits (PT) amongst South African women in HEIs is limited.

Whilst HEIs aim to rectify gender imbalances by increasing the number of female students and staff (Chimombo, 2003), the latter still experience marginalisation and exclusion from senior positions (Mama, 2003). It has been emphasised previously (Baxter, 2012) that gender discrimination, glass ceiling effects, and work-life balance struggles as well as work overload impact negatively on women's health and well-being (Mostert, 2009). Past research on gender within South Africa mainly focussed on ill health (Macik-Frey, Quick, Quick \& Nelson, 2009). However, with the recent shift towards positive psychology, research focus has been directed towards optimal health and well-being of women at work within African contexts (Darkwah, 2007; Louw, Mayer \& Surtee, 2014; Opie \& Henn, 2013). 
With the increase of women in HEIs, research is needed that focusses not only on traditional concepts of women as caregivers (Boadu, 2000), but rather on women in 'feminine leadership' (Powell, Butterfield \& Parent, 2002). Further research is needed on the sustainability of health and wellbeing of women from a positive psychology perspective (Mayer \& Van Zyl, 2013). Previous research on (black) women in HEIs shows that women feel (1) challenged by 'Old Boy Networks', (2) isolated and disrespected, (3) salient of race and gender, (4) under or overloaded with work, (5) torn between family, community and career and (6) challenged by students (Viernes Turner, 2002, p. 77). These factors may attribute to a decline in well-being of women (Mayer \& Van Zyl, 2013) and could affect work-related performance (Mostert, 2009).

Concepts, such as PT, SOC and MI, and their relationship within women in HEIs are described and investigated in this article to lay a foundation for scholarly inquiry regarding health and well-being in women. PT (extraversion and openness to experience) were shown to act as buffers against the effects of negative work or life demands (Latzman \& Masuda, 2013), SOC and MI support female leaders in overcoming work challenges (Louw et al., 2014; Mayer, 2011) and PT and SOC are interrelated (Hochwälder, 2012; Kardum \& Hudek-Knezevic, 2012; Latzman \& Masuda, 2013). A meta-analysis indicated that MI is related to PT with the strongest correlations being between MI, neuroticism, negative affect and conscientiousness (Giluk, 2009).

The purpose of this paper is to determine the relationship between PT, MI and SOC of women working in South African HEIs. The study thereby contributed to the knowledge on PT, MI and SOC amongst women working in HEIs.

\section{Literature review}

\section{Personality traits}

The Big Five PT Questionnaire is based on one of the most cited models on personality research (Judge \& Zapata, 2014). The Big Five PT provides understanding of PT at a broader level, including (1) extraversion (the extent an individual derives energy from both the social and material world and includes traits such as activity, assertiveness and sociability), (2) agreeableness (an orientation associated with altruistic, sympathetic and tender-minded interaction towards others), (3) conscientiousness (the extent of an individual's preference for self-control in relation to planning, organising and execution of tasks), (4) neuroticism (a dimension of normal personality associated with a tendency towards experiencing negative and dysfunctional emotions) and (5) openness to experience (the experience and acceptance of the breadth, depth, complexity and originality of one's psychological and experiential life and it includes traits such as an active imagination, sensitiveness to inner feelings, a preference for variety and acceptance of change) (Rothmann \& Coetzer, 2003).

PTs aided individuals to cope with and meet the demands of physical, social and cultural environments (Mc Donald,
1998). Laher and Croxford (2013) emphasised the need to research PT in the context of gender in South African organisations, because international studies have highlighted gender differences in PT (McCrae et al., 2005). Neuroticism and agreeableness are more frequently associated with women (Williams, Satterwhite \& Best, 1999). Similarly, within a US sample, women were more likely to experience neuroticism, agreeableness and extraversion (Costa, Terracciano \& McCrae, 2001). In other countries women differed significantly in openness to experience and conscientiousness in relation to men (Costa et al., 2001). However, Hyde (2005) pointed out that there are more similarities across genders than differences. Within the African context, fewer gender differences are described than in European contexts (McCrae et al., 2005). Laher and Croxford (2013) presented differences with a moderate effect on neuroticism, anxiety, vulnerability, aesthetics, altruism, modesty and agreeableness.

\section{Mindfulness}

MI is defined as a product of spiritual practice, which manifests in non-judgemental acceptance, curiosity, and enthusiasm for life (Germer, 2005). Walach et al. (2006) indicated that MI is comprised of three components: (1) nonjudgemental acceptance (to accept current events or situations without judgement), (2) mindful presence (sustained awareness of mindful experiences over time) and (3) insight (deeper understanding of one's self, the environment and others in the present). Mindful persons are aware of their own actions, live in the present moment (Brown \& Ryan, 2003) and connect fully to the self and to others, whilst living through 'being' rather than through 'doing' (Kabat-Zinn, 2006). MI is associated with adopting a nonjudging, non-striving attitude, acceptance, non-attachment, gentleness and kindness (Schmidt, 2004). It is associated with psychological well-being (Brown, Ryan \& Creswell, 2007) and inversely associated with distress (Masuda, Prince \& Latzman, 2012). MI has been studied in (higher) educational contexts (Bush, 2011; Lawlor, 2014). MI in women has mainly been researched in clinical and experimental settings (Dobkin \& Zhao, 2011). Previous research (Louw et al., 2014) found a significant correlation between manageability and MI in the South African HEI context. However, very limited research on MI and its associations exists within the South African context (Van Zyl \& Rothmann, 2012).

\section{Sense of coherence}

SOC is a general life orientation (Antonovsky, 1979), which responded to the question of 'what keeps people healthy' (Antonovsky, 1987). SOC is based on three components, namely, comprehensibility (ones' understanding of the world), manageability (how one copes with challenges) and meaningfulness (how one is motivated through the construction of meaning in life). SOC is positively associated with various individual outcomes such as resilience, and mental and physical health (Morrison \& Clift, 2006). 
Women displayed relatively lower SOC than men (Antonovsky, 1987; Lindström \& Eriksson, 2005; Mayer, 2011). However, the mean scores for SOC in male and female students in Sweden were similar (Von Bothmer \& Fridlund, 2003), women in South Africa scored higher on meaningfulness than men (Louw, Mayer \& Baxter, 2012) and African and Indian women in South Africa experienced higher levels of SOC than Caucasians (Mayer \& Van Zyl, 2013). Previous research into SOC amongst female academics in two South African universities showed high burn-out and low SOC scores (Bezuidenhout \& Cilliers, 2010).

\section{Relationships between personality traits, mindfulness and sense of coherence}

SOC and MI are connected (Christopher et al., 2011) and both influenced women's health and well-being in various populations (Galantino, Baime, Maguire, Szapary \& Farrar, 2005; Grossman, Niemann, Schmidt \& Walach, 2004), effective coping (Brown \& Ryan, 2003) and resource-orientation (Walsh \& Shapiro, 2006). Additionally, MI and PT revealed strong associations (Chavers, 2013), impacted positively on health (Goodwin \& Friedman, 2006; Hayes, Luoma, Bond, Masuda \& Lillis, 2006) and were central components in cognitive and behavioural therapies (Latzman \& Masuda, 2013). MI correlated significantly with PT (Giluk, 2009), whilst MI was negatively associated with neuroticism and positively associated with conscientiousness (Latzman \& Masuda, 2013). However, further research is needed (Chavers, 2013; Latzman \& Masuda, 2013).

SOC correlated with PT (Hochwälder, 2012), whereas PT explained a substantial part of the variability in SOC (Hochwälder, 2012) and extraversion, neuroticism and openness were represented in health-related concepts much more than agreeableness and conscientiousness (Kardum \& Hudek-Knezevic, 2012).

\section{Research objectives and hypotheses}

Based on the literature review it is hypothesised that interrelationships exist between the PT, MI and SOC of working women within South African HEIs These constructs are measured by the Big Five Inventory (BFI), Freiburger Mindfulness Inventory (FMI-14) and Life Orientation Questionnaire (LOQ). It has been pointed out that PT influence SOC, MI influences SOC, PT influence MI and PT influence MI which influences SOC. These relationships thus suggest that PT and MI be regarded as the independent variables and SOC as the dependent variable. The hypotheses are presented as follows:

- Hypothesis 1: There are positive correlations between PT (extraversion, agreeableness, conscientiousness and openness), MI and SOC for women employed in South African HEIs.

- Hypothesis 2: The PT construct of neuroticism correlates negatively with MI and SOC for women employed in South African HEIs.
- Hypothesis 3: The independent variables, PT and MI, predict SOC for women employed within South African HEIs.

\section{Method \\ Research approach}

A cross-sectional survey-based correlational research design, in which self-administered questionnaires were utilised, was used to achieve the research objective.

\section{Participants and procedures}

Non-probability sampling was used in this study. Both snowball and convenience sampling were utilised to obtain a workable sample $(n=125)$. Initially questionnaires were distributed amongst 950 women belonging to the Higher Education Resource Services network in South Africa (HERS-SA), with a limited response rate $(n=80)$. Thereafter, potential participants were contacted and requested to forward the questionnaire to individuals who matched the sample criteria. Surveys were distributed through two channels, namely, hardcopies and electronically via email. The sample was therefore increased by 45 . The data was captured and processed through SPSS.

Table 1 indicates that the largest proportions of the female participants were English-speaking (47.2\%), married (56.0\%), and had two children (32\%). Many held doctoral degrees (48\%) and were employed in managerial positions (39.2\%) at HEIs.

\section{Measuring instruments}

A biographical questionnaire was used to gather biographic and demographic information on participants.

The 44-item BFI (Goldberg, 1993) was used to measure the various PT constructs, namely conscientiousness, openness, extraversion, agreeableness and neuroticism on a five-point Likert scale. Within South Africa, Rothmann and Coetzer (2003) found that the BFI produced acceptable levels of internal consistency ranging from 0.76 to 0.86 on Conscientiousness ( $\alpha=0.78$ ), Openness ( $\alpha=0.77$ ), Extraversion $(\alpha=0.83)$, Agreeableness $(\alpha=0.76)$ and Neuroticism $(\alpha=0.86)$.

The 14-item FMI-14 (Walach et al., 2006) was administered to measure participants' perceived level of MI. It measures awareness and the non-judgement of present moment experiences on a four-point Likert scale. Confirmatory analysis confirmed construct validity of the FMI-14 (Sauer, Walach, Offenbächer, Lynch \& Kohls, 2011) These authors have also reported external validation studies of the FMI-14 and an acceptable level of internal consistency $(\alpha=0.86)$. The instrument is widely used across cultures in clinical and nonclinical populations.

The 29-item LOQ; (Antonovsky, 1979) was used to determine the participants' SOC, including comprehensibility, 
TABLE 1: Characteristics of participants.

\begin{tabular}{|c|c|c|c|}
\hline Item & Category & Frequency & Percentage \\
\hline \multirow[t]{2}{*}{ Gender } & Female & 125 & 100 \\
\hline & Missing values & 0 & 0 \\
\hline \multirow[t]{8}{*}{ Age } & 29 to 35 years & 17 & 13.6 \\
\hline & 36 to 40 years & 17 & 13.6 \\
\hline & 41 to 45 years & 26 & 20.8 \\
\hline & 46 to 50 years & 20 & 16.0 \\
\hline & 51 to 55 years & 22 & 17.6 \\
\hline & 56 to 60 years & 17 & 13.6 \\
\hline & $61+$ years & 5 & 4.0 \\
\hline & Missing values & 1 & 0.8 \\
\hline \multirow[t]{10}{*}{ Language group } & Afrikaans & 34 & 27.2 \\
\hline & English & 59 & 47.2 \\
\hline & Sotho & 9 & 7.2 \\
\hline & Xhosa & 6 & 4.8 \\
\hline & Tswana & 9 & 7.2 \\
\hline & Zulu & 4 & 3.2 \\
\hline & Hindi & 1 & 0.8 \\
\hline & Sepedi & 1 & 0.8 \\
\hline & SiSwati & 1 & 0.8 \\
\hline & Missing values & 1 & 0.8 \\
\hline \multirow[t]{6}{*}{ Marital status } & Single & 36 & 28.8 \\
\hline & Married & 70 & 56.0 \\
\hline & Divorced & 12 & 9.6 \\
\hline & Living with a partner & 1 & 0.8 \\
\hline & Widow & 1 & 0.8 \\
\hline & Missing values & 5 & 4.0 \\
\hline \multirow[t]{3}{*}{ Children } & Yes & 92 & 73.6 \\
\hline & No & 30 & 24.0 \\
\hline & Missing values & 3 & 2.4 \\
\hline \multirow{6}{*}{$\begin{array}{l}\text { Number of } \\
\text { children }\end{array}$} & 1 child & 25 & 20.0 \\
\hline & 2 children & 40 & 32.0 \\
\hline & 3 children & 16 & 12.8 \\
\hline & 4 children & 3 & 2.4 \\
\hline & 5 or more children & 1 & 0.8 \\
\hline & Missing values & 7 & 5.6 \\
\hline \multirow[t]{7}{*}{ Level of education } & Doctoral degree & 60 & 48.0 \\
\hline & Master's degree & 43 & 34.4 \\
\hline & Honours degree & 9 & 7.2 \\
\hline & Graduate degree & 9 & 7.2 \\
\hline & Diploma & 3 & 2.4 \\
\hline & High school & 1 & 0.8 \\
\hline & Missing values & 0 & 0 \\
\hline \multirow[t]{4}{*}{ Current position } & Academic & 34 & 27.2 \\
\hline & Support Staff & 42 & 33.6 \\
\hline & Management & 49 & 39.2 \\
\hline & Missing values & 0 & 0 \\
\hline
\end{tabular}

$N=125$.

manageability and meaningfulness, on a seven-point Likert scale. Muller and Rothmann (2009) indicated that the LOQ produced acceptable levels of internal consistency on the various subscales $(0.80 \leq \alpha \leq 0.83)$. However, it is important to note that various factor structures and levels of internal consistency have been found within the South African context (Van Schalkwyk \& Rothmann, 2008).

\section{Design}

A cross-sectional survey-based correlational research design was used to gather data on the participants' PT, MI and SOC at a single point in time. Ethical guidelines were followed and ethical clearance for the project was obtained from Rhodes University, Grahamstown, South Africa.

\section{Data analysis}

The SPSS (SPSS Inc, 2012) statistical analysis package was used to process the data. Exploratory factor analysis, with principal component analysis was conducted to determine the factor structure of the items in the questionnaires. Sampling adequacy was determined by using Bartlett's test of Sphericity and the Kaiser-Meyer-Olkin measure to determine the factorability of the items. Principal axis factoring and either a varimax or direct oblimin rotation was performed to investigate the factor structure of the measuring instruments. The number of factors was determined through the use of the Kaiser criterion and eigenvalues $(\lambda>1)$ (Field, 2009). Cronbach's coefficient alphas were calculated to determine the internal consistency of the measuring instruments (Salkind, 2012).

Depending on the distribution, Pearson/Spearman correlation coefficients, with a significance level of $p<0.05$ (Field, 2009), were used to determine the relationships between the variables. Effect sizes were used to determine the practical significance of the correlational results (Steyn, 1999). The suggested cut-off points of 0.30 (medium effect) and 0.50 (large effect) were utilised in order to determine the level of practical significance (Field, 2009). Canonical correlations were computed to determine whether there were multiple relationships between the variables. Canonical correlations are used in order to determine the relationship between two sets of variables and a cut-off point of 0.30 was used (Tabachnick \& Fidell, 2001). Stepwise hierarchical multiple regression analyses (enter method) were carried out to determine the proportion of variance in SOC declared by PT and MI. Practical significance was again represented by Steyn's (1999) effect sizes (> 0.35 equals large effect) and was determined through the following formula: $f^{2}=R^{2} /\left(1-R^{2}\right)$.

\section{Results \\ Factor analysis}

Principal axis factoring with a varimax rotation was conducted on the 44 items of the BFI. The scale produced individual factor loadings which were higher than Field's (2009) suggested 0.30 for the majority of the items. However, 10 items $(3,12,18,23,30,33,34,35,41$ and 42$)$ had to be removed from further analysis as they did not conform to the suggested communality cut-offs. The initial Kaiser-Meyer-Olkin measure of sampling adequacy revealed a value of 0.77 which, according to Field (2009), indicates that the items were factorable. Furthermore, Bartlett's test of sphericity was significant $\left(\chi_{(561)}^{2}=1859.60 ; p<0.01\right)$. Kaiser criterion resulted in five factors being extracted (cumulative $R^{2}=45.41 \%$ ). The first factor was labelled Extraversion $\left(\lambda=6.40 ; R^{2}=18.81 \% ; \alpha=\right.$ $0.85)$, the second Neuroticism $\left(\lambda=3.77 ; R^{2}=11.07 \% ; \alpha=0.79\right)$ the third Conscientiousness $\left(\lambda=3.36 ; R^{2}=9.88 \% ; \alpha=0.74\right)$, the fourth Agreeableness $\left(\lambda=2.17 ; R^{2}=6.39 \% ; \alpha=0.79\right)$ and, finally, Openness $\left(\lambda=1.93 ; R^{2}=5.68 \% ; \alpha=0.76\right)$. 
Principal axis factoring with a direct oblimin rotation was utilised on the 14 items of the FMI-14. The scale produced factor loadings which were higher than Field (2009) suggested (0.30), with the exception of items 13 and 14 (which were removed from further analysis). The initial Kaiser-MeyerOlkin measure of sampling adequacy revealed a value of 0.83 which, according to Field (2009), indicates that the items were factorable. Furthermore, Bartlett's test of sphericity was shown to be highly significant $\left(\chi_{(45)}^{2}=318.31 ; p<0.01\right)$. Eigenvalues $(>1)$ resulted in three factors being extracted (cumulative $R^{2}=62.64 \%$ ). The first factor was labelled Nonjudgemental acceptance $\left(\lambda=3.86 ; R^{2}=38.59 \% ; \alpha=0.78\right)$, the second Insight $\left(\lambda=1.23 ; R^{2}=12.31 \% ; \alpha=0.73\right)$ and the third Mindful presence $\left(\lambda=1.17 ; R^{2}=11.74 \% ; \alpha=0.71\right)$.

Principal axis factoring with a varimax rotation was utilised on the 29 items of the LOQ. The initial Kaiser-Meyer-Olkin measure of sampling adequacy revealed a value of 0.85 which, according to Field (2009), indicates that the items were factorable. Furthermore, Bartlett's test of sphericity produced highly significant results $\left(\chi_{(136)}^{2}=739.03 ; p<0.01\right)$. The scale produced factor loadings which were higher than Field's (2009) suggested 0.30. Both the Kaiser criterion, as well as eigenvalues, resulted in three factors being extracted (cumulative $R^{2}=55.68 \%$ ). The first factor was labelled Comprehensibility $\left(\lambda=5.20 ; R^{2}=32.49 \% ; \alpha=0.83\right)$, the second Manageability $\left(\lambda=2.25 ; R^{2}=14.08 \% ; \alpha=0.65\right)$ and the third Meaningfulness $\left(\lambda=1.46 ; R^{2}=9.11 \% ; \alpha=0.76\right)$.

\section{Descriptive statistics and correlations}

The descriptive statistics in relation to means, standard deviations, skewness, kurtosis and Cronbach alpha coefficients, as well as the correlations are reported in Table 2, which shows that all scales show sufficient reliability $(\alpha>$ 0.60 ) with alpha values varying from 0.65 to 0.85 (Nunnally, 1978). With the exception of Comprehensibility and Openness, all factors were normally distributed.

The following statistically $(p<0.01)$ and practically significant $(r>0.30)$ correlations were found: Comprehensibility correlated positively with Manageability, Non-judgemental acceptance, Insight, Agreeableness and negatively with Neuroticism, all with a medium effect. The results showed that a significant positive relationship exists between Manageability and Non-judgemental acceptance, Insight, Conscientiousness as well as a negative relationship with Neuroticism, with a medium effect. Furthermore, Nonjudgemental acceptance correlated positively with Mindful presence and negatively with Neuroticism (with a large effect) as well as positively with Insight and Agreeableness (with a medium effect). Insight correlated positively with Mindful presence, Agreeableness and negatively with Neuroticism (with a medium effect). Mindful presence correlated positively with Extraversion (with a medium effect). Extraversion only positively correlated with Agreeableness, with a medium effect. Similarly, Agreeableness correlated positively with Openness, with a medium effect. Agreeableness correlated negatively with Neuroticism, with a large effect (Table 2).

The magnitude and extent of the intercorrelations given in Table 2 are therefore evidence that Hypotheses 1 and 2 may be partially accepted.

\section{Multivariate statistics}

Canonical correlations were subsequently performed to determine whether there were multiple relationships between the variables. The Wilks-Lambda test of significance indicated that the results were statistically significant ( $p=$ 0.001). The $p$ value was below 0.01 in order to indicate significance and reliability of the results (Tabachnick \& Fidell, 2001). Therefore, a significant canonical correlation was produced at 0.72 with $51.51 \%$ overlapping variance. The first $F$-test $\left(F_{(30,362)}=4.46 p<0.05\right)$ produced statistically significant results. The second $F$-test $\left(F_{(20,302.67)}=2.65 p>0.05\right)$, third $F$-test $\left(F_{(12,243.7)}=2.15 p>0.05\right)$, fourth $F$-test $\left(F_{(6,186)}=1.41 p>\right.$ $0.05)$ and fifth $F$-test $\left(F_{(2,94)}=0.24 p>0.05\right)$ were not statistically significant. Tabachnick and Fidell (2001) indicated that only canonical correlations with medium to high $(>0.30)$ effects should be interpreted (Table 3).

TABLE 2: Descriptive statistics, reliabilities and correlations between sense of coherence, mindfulness and Big 5 personality traits.

\begin{tabular}{|c|c|c|c|c|c|c|c|c|c|c|c|c|c|c|c|}
\hline Item & Mean & SD & Skewness & Kurtosis & $\alpha$ & 1 & 2 & 3 & 4 & 5 & 6 & 7 & 8 & 9 & 10 \\
\hline \multicolumn{16}{|l|}{ Sense of coherence } \\
\hline Comprehensibility & 2.23 & 0.93 & 1.27 & 3.09 & 0.83 & - & - & - & - & - & - & - & - & - & - \\
\hline Manageability & 4.86 & 0.74 & -0.30 & -0.30 & 0.65 & $0.46 * \dagger$ & - & - & - & - & - & - & - & - & - \\
\hline Meaningfulness & 3.68 & 1.41 & 0.09 & -0.87 & 0.76 & 0.01 & $0.28 *$ & - & - & - & - & - & - & - & - \\
\hline \multicolumn{16}{|l|}{ Mindfulness } \\
\hline Non-judgemental acceptance & 2.80 & 0.65 & -0.22 & -0.30 & 0.78 & $0.32 * \dagger$ & $0.32 * \dagger$ & 0.08 & - & - & - & - & - & - & - \\
\hline Insight & 3.05 & 0.61 & -0.62 & 0.49 & 0.73 & $0.33 * \dagger$ & $0.30 * \dagger$ & -0.15 & $0.39 * \dagger$ & - & - & - & - & - & - \\
\hline Mindful presence & 3.08 & 0.58 & -0.16 & -0.72 & 0.71 & $0.28 *$ & $0.26^{*}$ & 0.06 & $0.50 * \psi$ & $0.35 * \dagger$ & - & - & - & - & - \\
\hline \multicolumn{16}{|l|}{ Personality traits } \\
\hline Extraversion & 3.58 & 0.87 & -0.35 & -0.70 & 0.85 & $0.26 *$ & -0.01 & -0.12 & $0.24 *$ & 0.09 & 0.15 & - & - & - & - \\
\hline Agreeableness & 4.10 & 0.56 & -0.52 & -0.15 & 0.79 & $0.33^{*} \dagger$ & $0.23 *$ & 0.13 & $0.30 * \dagger$ & $0.34 * \dagger$ & $0.31 * \dagger$ & 0.14 & - & - & - \\
\hline Conscientiousness & 4.16 & 0.54 & -0.51 & -0.45 & 0.74 & 0.17 & $0.42 * \dagger$ & 0.07 & 0.06 & 0.09 & 0.18 & -0.14 & 0.17 & - & - \\
\hline Neuroticism & 2.44 & 0.70 & 0.51 & 0.65 & 0.79 & $-0.39 * \dagger$ & $-0.46 * \dagger$ & -0.10 & $-0.56 * \ddagger$ & $-0.47 * \dagger$ & $-0.28 *$ & $-0.19 *$ & $-0.50 * \dagger$ & $-0.25^{*}$ & - \\
\hline Openness & 3.91 & 0.58 & -0.53 & 1.08 & 0.76 & $0.25 *$ & 0.09 & -0.10 & 0.17 & $0.27 *$ & $0.28 *$ & $0.31 * \dagger$ & $0.23 *$ & 0.10 & -0.08 \\
\hline
\end{tabular}


The first canonical variate accounted for a significant relationship between the antecedent and outcome variable sets. Regarding Tabachnick and Fidell's (2001) suggested cut-off score of 0.30, only Agreeableness (-0.49), Neuroticism (0.94) and Openness $(-0.38)$ correlated with the first canonical variate within theantecedentset. In the outcomeset, only Meaningfulness $(-0.06)$ did not correlate with the first canonical variate. This implies that the first canonical variate indicates that lower levels of Manageability, Non-judgemental acceptance, Insight and Mindful presence, coupled with higher levels of Comprehensibility, are associated with lower levels of Agreeableness and Openness as well as higher levels of Neuroticism.

These findings provide further evidence for the acceptance of Hypotheses 1 and 2.

\section{Multiple regressions}

To determine if PT (Extraversion, Agreeableness, Conscientiousness Neuroticism, Openness) and MI (Nonjudgemental acceptance, Insight, Mindful presence) predict

TABLE 3: Results of canonical analysis: Big 5 personality traits, mindfulness and sense of coherence.

\begin{tabular}{lcc}
\hline Antecedent and & \multicolumn{2}{c}{ First canonical variate } \\
\cline { 2 - 3 } outcome variables & Correlation & Coefficient \\
\hline Antecedents set & - & - \\
Extraversion & -0.27 & -0.02 \\
Agreeableness & -0.49 & 0.03 \\
Conscientiousness & -0.22 & 0.04 \\
Neuroticism & 0.94 & 0.94 \\
Openness & -0.38 & -0.33 \\
Percent of variance & 14.35 & - \\
Redundancy & 27.86 & - \\
Outcomes set & - & - \\
Comprehensibility & 0.54 & 0.54 \\
Manageability & -0.63 & -0.63 \\
Meaningfulness & -0.06 & -0.06 \\
Non-judgemental acceptance & -0.80 & -0.80 \\
Insight & -0.74 & -0.74 \\
Mindful presence & -0.42 & -0.42 \\
Percent of variance & 34.32 & - \\
Redundancy & 17.68 & - \\
Canonical correlation & 0.72 & - \\
\hline
\end{tabular}

SOC (Comprehensibility, Manageability, Meaningfulness), three multiple regression analyses were conducted, by means of the so-called enter method, namely the simultaneous entry of the independent variables. The results of the multiple regression analyses are presented in Tables 4 and 5 .

Table 4 summarises the regression analyses with PT (Extraversion, Agreeableness, Conscientiousness Neuroticism, Openness) and MI (Non-judgemental acceptance, Insight, Mindful presence) as the predictors of Comprehensibility. Both the first and second model did not produce a practically significant effect size $\left(f^{2}<0.35\right)$. MI was entered at the first step of the regression and produced a statistically significant model $\left(F_{(3,118)}=5.94 ; p=0.00\right)$ that accounted for $13 \%$ of the variance. Only Insight $(\beta=0.24 ; t=$ 2.57; $p \leq 0.05$ ) predicted Comprehensibility in the first model. When PT were entered into the second step of the analysis, a statistically significant model $\left(F_{(8,113)}=3.94 ; p=0.00\right)$ was produced which explained $22 \%$ of the total variance. Here, only Neuroticism $(\beta=-0.23 ; t=-1.91 ; p \leq 0.05)$ predicted Comprehensibility.

Similarly, Table 5 summarises the regression analyses with PT and MI as the predictors of Manageability. MI was entered at the first step of the regression analysis and produced a statistically significant model $\left(F_{(3,116)}=5.91 ; p=0.00\right)$ that accounted for $13 \%$ of the variance. The first model did not produce a practically significant effect size $\left(f^{2}<0.35\right)$. Only Insight $(\beta=0.18 ; t=1.90 ; p \leq 0.05)$ predicted Manageability in the first model. When PT were entered into the second step of the analysis, a statistically significant model $\left(F_{(8,11)}=7.74 ; p=\right.$ $0.00)$ was produced which explained $36 \%$ of the total variance. The second model produced a practically significant effect size $\left(f^{2}>0.35\right)$. Both Conscientiousness $(\beta=0.30 ; t=3.46 ; p \leq$ $0.05)$ and Neuroticism $(\beta=-0.40 ; t=-3.60 ; p \leq 0.050)$ are significant predictors of Manageability in the second model.

Finally, PT and MI were entered as the predictors of Meaningfulness. MI was entered at the first step $\left(F_{(3,119)}=2.29\right.$; $p=0.08)$ and PT at the second step $\left(F_{(8,114)}=1.90 ; p=0.06\right)$ of the regression analysis. Neither produced statistically or practically significant models.

TABLE 4: Multiple regression analysis with comprehensibility as a dependent variable.

\begin{tabular}{|c|c|c|c|c|c|c|c|c|c|c|c|}
\hline \multirow[t]{2}{*}{ Model } & \multirow[t]{2}{*}{ Predictor variables } & \multicolumn{2}{|c|}{ Unstandardised coefficients } & \multirow{2}{*}{$\begin{array}{c}\text { Standardised } \\
\text { coefficients: } \\
\text { Beta }\end{array}$} & \multirow[t]{2}{*}{$t$} & \multirow[t]{2}{*}{$p$} & \multirow[t]{2}{*}{$F$} & \multirow[t]{2}{*}{$R$} & \multirow[t]{2}{*}{$R^{2}$} & \multirow[t]{2}{*}{$\Delta R^{2}$} & \multirow[t]{2}{*}{$f^{2}$} \\
\hline & & B & SE & & & & & & & & \\
\hline \multirow[t]{4}{*}{1} & (Constant) & 4.30 & 0.52 & - & 8.35 & 0.00 & \multirow{4}{*}{5.94} & \multirow{4}{*}{0.36} & \multirow{4}{*}{0.13} & \multirow{4}{*}{0.13} & \multirow{4}{*}{0.15} \\
\hline & Non-judgemental acceptance & 0.14 & 0.15 & 0.10 & 0.96 & 0.34 & & & & & \\
\hline & Insight & 0.37 & 0.14 & 0.24 & 2.57 & 0.01 & & & & & \\
\hline & Mindful presence & 0.18 & 0.16 & 0.11 & 1.12 & 0.26 & & & & & \\
\hline \multirow[t]{8}{*}{2} & (Constant) & 3.96 & 1.32 & - & 3.00 & 0.00 & \multirow{8}{*}{3.94} & \multirow{8}{*}{0.47} & \multirow{8}{*}{0.22} & \multirow{8}{*}{0.09} & \multirow{8}{*}{0.28} \\
\hline & Non-judgemental acceptance & 0.04 & 0.16 & 0.03 & 0.23 & 0.82 & & & & & \\
\hline & Insight & 0.19 & 0.15 & 0.13 & 1.27 & 0.21 & & & & & \\
\hline & Mindful presence & 0.13 & 0.17 & 0.08 & 0.75 & 0.46 & & & & & \\
\hline & Extraversion & 0.16 & 0.10 & 0.15 & 1.60 & 0.11 & & & & & \\
\hline & Agreeableness & 0.04 & 0.16 & 0.03 & 0.26 & 0.80 & & & & & \\
\hline & Conscientiousness & 0.05 & 0.16 & 0.03 & 0.28 & 0.78 & & & & & \\
\hline & Neuroticism & -0.29 & 0.15 & -0.23 & -1.91 & 0.05 & & & & & \\
\hline
\end{tabular}


TABLE 5: Multiple regression analysis with manageability as a dependent variable.

\begin{tabular}{|c|c|c|c|c|c|c|c|c|c|c|c|}
\hline \multirow[t]{2}{*}{ Model } & \multirow[t]{2}{*}{ Predictor variables } & \multicolumn{2}{|c|}{ Unstandardised coefficients } & \multirow{2}{*}{$\begin{array}{l}\text { Standardised } \\
\text { coefficients: } \\
\text { Beta }\end{array}$} & \multirow[t]{2}{*}{$t$} & \multirow[t]{2}{*}{$\bar{p}$} & \multirow[t]{2}{*}{$F$} & \multirow[t]{2}{*}{$R$} & \multirow[t]{2}{*}{$R^{2}$} & \multirow[t]{2}{*}{$\Delta R^{2}$} & \multirow[t]{2}{*}{$f^{2}$} \\
\hline & & B & SE & & & & & & & & \\
\hline \multirow[t]{3}{*}{1} & (Constant) & 3.09 & 0.45 & - & 6.94 & 0.00 & \multirow{3}{*}{5.91} & \multirow{3}{*}{0.36} & \multirow{3}{*}{0.13} & \multirow{3}{*}{0.13} & \multirow{3}{*}{0.15} \\
\hline & Insight & 0.23 & 0.12 & 0.18 & 1.90 & 0.05 & & & & & \\
\hline & Mindful presence & 0.22 & 0.14 & 0.16 & 1.53 & 0.13 & & & & & \\
\hline \multirow[t]{8}{*}{2} & (Constant) & 3.84 & 1.03 & - & 3.74 & 0.00 & \multirow{8}{*}{7.74} & \multirow{8}{*}{0.60} & \multirow{8}{*}{0.36} & \multirow{8}{*}{0.23} & \multirow{8}{*}{0.56} \\
\hline & Insight & 0.05 & 0.12 & 0.04 & 0.46 & 0.65 & & & & & \\
\hline & Mindful presence & 0.22 & 0.14 & 0.15 & 1.61 & 0.11 & & & & & \\
\hline & Extraversion & -0.03 & 0.08 & -0.03 & -0.33 & 0.74 & & & & & \\
\hline & Agreeableness & 0.11 & 0.11 & 0.09 & 0.98 & 0.33 & & & & & \\
\hline & Conscientiousness & 0.44 & 0.13 & 0.30 & 3.46 & 0.00 & & & & & \\
\hline & Neuroticism & -0.43 & 0.12 & -0.40 & -3.60 & 0.00 & & & & & \\
\hline & Openness & 0.01 & 0.11 & 0.01 & 0.08 & 0.94 & & & & & \\
\hline
\end{tabular}

Hypothesis 3 was therefore partially accepted.

\section{Discussion}

\section{Psychometric properties of scales}

Exploratory factor analyses confirmed the factor structure for the three scales used in this study. Ang et al.'s (2007) factor structure and reliability of the Big 5 PT questionnaire was partially confirmed in this study. As with numerous publications within the South African context (c.f. Laher, 2010; Louw \& Viviers, 2010; Morgan \& De Bruin, 2010; Ramsay, Taylor, De Bruin \& Meiring, 2005; Rothmann \& Coetzer, 2002, 2003), the Big 5 PT questionnaire did not completely conform to the originally suggested factor structure (Costa \& McCrae, 1989). Ten items were removed in order to enhance the factorability, factor structure and, by implication, the reliability of the questionnaire. These items were predominantly within the conscientiousness and agreeableness scales, similar to the findings of Ramsay et al. (2005). Further investigation into the conceptualisation of the 'African personality' (Ramsay et al., 2005) is needed in order to enhance the factorability of the questionnaire.

Similarly, the FMI-14 MI scale produced a structurally sound and reliable three factor model for MI within the sample group after two items ( 12 - 'I am impatient with myself and with others'; 13 - 'I am able to smile when I notice how I sometimes make life difficult') were removed. Although the questionnaire produced reliable results, it provided evidence for a two, three and four factor structure. This is in support of the Sauer et al. (2011) as well as Walach et al.'s (2006) findings. The FMI has not been extensively used within the South African environment, and as such no comparisons could be made on a national level.

Finally, the LOQ produced a three factor model similar to various South African studies (c.f. Herbst, Coetzee \& Visser, 2007; Van Schalkwyk \& Rothmann, 2008) and produced acceptable reliabilities. Although the factor structure was confirmed, some of the item loadings are not in line with Antonovsky's (1987) proposed factor to item loading structure. Three of the original comprehensibility items (1, $10,15,26)$ loaded on manageability. Similarly, two items traditionally associated with manageability $(18,27)$ loaded on comprehensibility. It would therefore seem that the concepts of comprehensibility and manageability may be intertwined in the current sample. Antonovsky (1987) did however argue that there may be shared variance between the three components of SOC, which could provide an explanation for the unintended overlap. Van Schalkwyk and Rothmann (2008) argued that the LOQ may present an unstable factor structure within the South African context and that further research is required to refine the measurement of SOC within South Africa.

\section{Relationships amongst variables}

The product-moment correlational analysis between PT, MI and SOC showed that significant relationships between these variables exist. Furthermore, canonical correlations showed that a combination of lower levels of manageability, nonjudgemental acceptance, insight and mindful presence, coupled with higher levels of comprehensibility is associated with lower levels of agreeableness and openness as well as higher levels of neuroticism within this sample.

This implies that women within this sample, who perceive the world to be structured, ordered and consistent are likely to show the ability to cope with life-related demands. This may be as a result of the ability to accept life-related events without judgement which related to a deeper level of understanding of these challenges (Chavers, 2013). Furthermore, high levels of comprehensibility were also associated with agreeableness and lower levels of neuroticism within the sample. Individuals who perceived life to be predictable and consistent could experience higher levels of emotional stability (i.e. low neuroticism) and could be less prone to present irrational beliefs/ideas and cope effectively with life's challenges (Feldt, Metsäpelto, Kinnunen \& Pulkkinen, 2007). Comprehensibility was also associated with the agreeable PT. This may be because individuals who felt in control of life and the associative demands are more likely to be sympathetic to others (Feldt et al., 2007). 
Similarly, non-judgemental acceptance, insight and conscientiousness were positively associated with manageability. Individuals who believe they can cope with life demands are also able to unconditionally accept these events, without judgement, and are likely to present with deeper levels of understanding of their causality and implication. This is consistent with previous research which found that MI positively relates individual health-related outcomes (Dobkin \& Zhao, 2011). Applied research suggests that MI could act as a positive contributor to the activation of internal resources needed to enhance SOC (Carmody, Reed, Kristeller \& Merriam, 2008).

In contrast, neuroticism was negatively associated with manageability. Individuals that are unable to cope with life demands are also likely to present with higher levels of emotional instability (i.e. neuroticism). This is in line with the findings of Feldt et al. (2007). Individuals who were not emotionally mature and unable to manage their emotions, were more likely to perceive stressful events as unmanageable (Feldt et al., 2007; Hochwälder, 2012). This study negates the findings that neuroticism and SOC lay on a continuum (Feldt et al., 2007; Gibson \& Cook, 1996). Although comprehensibility and manageability are negatively related to neuroticism, meaningfulness showed no significant relationship thereto. Also, the strength of the negative relationship between components of SOC and neuroticism within this study (comprehensibility: -0.39; manageability: -0.46) is not strong enough to justify the assumption that these variables are presented on a continuum.

In this study, the three components of MI, non-judgemental acceptance, insight and mindful presence, were positively related. This is in line with Sauer et al. (2011) and Walach et al.'s (2006) conceptualisation who argued that these components have shared variance. As with the components of SOC, agreeableness correlated positively with the three components of MI. It would seem as though individuals who live in and appreciate positive moments in the present are able to manage interpersonal relationships well. Living in the present may accentuate the immediate importance and value of interpersonal relationships. Neuroticism related negatively with a relatively large effect to both non-judgemental acceptance and insight. By implication, individuals presenting with low levels of emotional stability (i.e. high neuroticism) may be more judgemental and show lower sympathy or empathy towards others. This may be as a result of how neuroticism overwhelms an individual with emotions in the present whereby one would be unable to appreciate the perspectives of others.

Within this sample, only four PT related significantly to the other. Extraversion related positively with openness. This implies extraverts are more likely to be flexible and open to new experiences than introverts. Furthermore, agreeableness related negatively to neuroticism with a large effect. This research supports the findings of Feldt et al. (2007). By implication, those who are able to foster and build positive relationships are also able to manage their emotions and emotional reactions to situations.

\section{Personality traits and mindfulness as predictors of sense of coherence}

The final hypothesis of this study was the extent to which PT and MI acted as predictors of SOC. The results of the first step of the multiple regression analyses showed that only insight acted as a predictor for comprehensibility and manageability. The results of the second step of the multiple regression analyses showed that when entering PT into the equation, only neuroticism acted as a predictor of comprehensibility and that manageability is only predicted by conscientiousness and neuroticism. Furthermore, neither MI nor PT could predict meaning within this sample.

This implies that, in isolation, insight could accurately predict a portion of comprehensibility and manageability. Therefore, if insight could be developed in women within this sample, it should have an effect on the occurrence of two of the components of SOC. It is obvious that insight impacts on the way how a person understands the world and on how an individual copes with challenges.

Similarly, in relation to MI, neuroticism could predict lower levels of comprehensibility and manageability within this sample. This could be because neuroticism has repeatedly been shown as a PT that is associated with negative emotions, distress and depression and with a range of psychopathology (Latzman \& Masuda, 2013) which might impact negatively on the way of understanding the world and coping with challenges.

Conscientiousness, in relation to MI, could also act as a predictor for manageability. Conscientiousness as an impulse control ability and the ability to pay attention to detail could, in relation to MI, be a predictor for manageability, because of the assumption that being present, aware and conscientious might provide the individual with the awareness of the needed coping resources. The detailed perception helps the individual to activate the needed resources at the right point in time.

\section{Practical implications for Human Resource Management}

The findings confirm that certain PT (conscientiousness, neuroticism) and insight (as a component of MI) could predict comprehensibility and manageability (as components of SOC) within a sample of female employees in HEIs and thereby impact on organisational health and well-being on a broader scale. The practical implications for HRM might include to value PT and MI as strengthening resources to predict comprehensibility and manageability (SOC). Therefore, HRM should focus on PT, MI and SOC in selection processes, in training and in developing careers of women, particularly focussing on these components of sustainable mental health and well-being. Human Resource (HR) 
managers should be aware of these components and need to be trained to understand the intrapsychological impacts of mental health and well-being in the workplace.

\section{Limitations}

The first limitation relates to the cross-sectional research design, which could provide no indication of causal relationships. Future studies should aim to utilise longitudinal research designs to provide a deeper understanding on the causality of the relationships. Similarly, a predictive validity design was not utilised, which may have affected the magnitude of the correlation coefficients. Secondly, the sampling method may have attributed to positivity bias whereas a random sampling technique could have been used to enhance the generalisability of the results and representativeness of the sample. Thirdly, given the nature and availability of the sample, future studies should utilise alternative distribution methods such as user-friendly online surveys hosted on a neutral webserver. Fourthly, the relatively small sample size limits the type of statistical analysis which could be used to analyse the data. Future studies should aim to increase the sample size to at least 350 in order to utilise structural equation or latent variable modelling. The low response rate affects the generalisability of the results. Fifthly, it is suggested that a thorough investigation into the psychometric properties of the FMI-14 be conducted to establish the reliability and validity of the instrument in a multi-cultural southern African context. Therefore, the relationship between PT, MI and within HEIs should be studied within larger, stratified-random samples through utilising predictive validity designs. Sixthly, given the nature of the demographic and biographic position of the sample, a clear cultural bias is present. The results should therefore be interpreted against this backdrop.

\section{Conclusion}

The aim of this study was to investigate the relationship between PT, MI and SOC of women working in HEIs in South Africa. The results indicate that all the measuring instruments were reliable sources of information to address the primary aim of this project. With a few exceptions, correlational analysis produced both practically and statistically significant relationships between the various components of personality, MI and SOC within this sample. The results of the canonical correlations indicated that approximately $51.51 \%$ of the variance could be explained by the combination of lower levels of manageability, nonjudgemental acceptance, insight and mindful presence, coupled with higher levels of comprehensibility, which are associated with lower levels of agreeableness and openness as well as higher levels of neuroticism within this sample. Finally, hierarchical multiple regressions indicated that only certain PT (conscientiousness, neuroticism) and insight (as a component of MI) could predict comprehensibility and manageability (as components of SOC) within a sample of female employees HE environments.

\section{Acknowledgements Competing interests}

The authors declare that they have no financial or personal relationships which may have inappropriately influenced them in writing this article.

\section{Authors' contributions}

C-H.M. was the project leader, S.S. made conceptual contributions and D.V. made contributions to the research methodology and statistical analysis and interpretation.

\section{References}

Ang, S., Van Dyne, L., Koh, C., Ng, K.Y., Templer, K.J., Tay, C., et al. (2007). Cultural intelligence: Its measurement and effects on cultural judgment and decision making, cultural adaptation, and task performance. Management and Organization making, cultural adaptation, and task performance. Management and Organizd
Review, 3, 335-371. http://dx.doi.org/10.1111/j.1740-8784.2007.00082.x

Antonovsky, A. (1979). Health, stress and coping. San Francisco, CA: Jossey-Bass.

Antonovsky, A. (1987). Unravelling the mystery of health: How people manage stress and stay well. San Francisco, CA: Jossey-Bass.

Baxter, J. (2012). Feminist research. The Encyclopaedia of Applied Linguistics, 17(2), 107-116. http://dx.doi.org/10.1002/9781405198431.wbeal0412

Bezuidenhout, A., \& Cilliers, F.V.N. (2010). Burnout, work engagement and sense of coherence in female academics in higher-education institutions in South Africa. South African Journal of Industrial Psychology, 36(1), 1-10. http://dx.doi. org/10.4102/sajip.v36i1.872

Boadu, J.N.A. (2000). The health of working mothers in Accra: A case study of doctors and nurses at the Kolre-bu Teaching Hospital and workers at North Gbawe Stone Quarry. M.Phil. thesis. Accra, Ghana: Institute of African Studies.

Brown, K., \& Ryan, R. (2003). The benefits of being present: Mindfulness and its role in psychological well-being. Journal of Personality and Social Psychology, 84, 822-848. http://dx.doi.org/10.1037/0022-3514.84.4.822

Brown, K., Ryan, R.M., \& Creswell, J. (2007). Mindfulness: Theoretical foundations and evidence for its salutary effects. Psychological Inquiry, 18(4), 211-237. http://dx. doi.org/10.1080/10478400701598298

Bush, M. (2011). Mindfulness in higher education. Contemporary Buddhism, 12(1) 183-197. http://dx.doi.org/10.1080/14639947.2011.564838

Carmody, J., Reed, G., Kristeller, J., \& Merriam, P. (2008). Mindfulness, spirituality, and health-related symptoms. Journal of Psychosomatic Research, 64(4), 393-403. http://dx.doi.org/10.1016/j.jpsychores.2007.06.015

Chavers, D.J. (2013). Relationships between spirituality, religiosity, mindfulness, personality, and resilience. Master thesis, University of Alabama. Ann Arbor, MI: Pro Quest.

Chimombo, J.P.G. (2003). Malawi. In D. Teferra \& P.G. Altbach (Eds.), African higher education: An international reference Handbook (pp. 595-600). Bloomington, IN Indiana University Press.

Christopher, J.C., Chrisman, J.A., Trotter-Mathison, M.J., Schure, M.B., Dahlen, P., \& Christopher, S.B. (2011). Perception of the long-term influence of mindfulness training on counsellors and psychotherapists: A qualitative inquiry. Journal of Humanistic Psychology, 51(3), 318-349. http://dx.doi.org/10.1177/ 0022167810381471

Costa, P.T. Jr., \& McCrae, R.R. (1989). The NEO-PI/NEO-FFI manual supplement. Odessa, FL: Psychological

Costa, P.T., Terracciano, A., \& McCrae, R.R. (2001). Gender differences in personality traits across cultures: Robust and surprising findings. Journal of Personality and Social Psychology, 81, 322-331. http://dx.doi.org/10.1037/00223514.81.2.322

Darkwah, A. (2007). Work as a duty and as a joy: Understanding the role of work in the lives of Ghanaian female traders of global consumer items. In S. Harley (Ed.) Women's labor in the global economy: Speaking in multiple voices (pp. 206-220). New Brunswick, NJ: Rutgers University Press.

Dobkin, P.L., \& Zhao, Q. (2011). Increased mindfulness - The active component of the mindfulness-based stress reduction program? Complementary Therapies in Clinical Practice, 17(1), 22-27. http://dx.doi.org/10.1016/j.ctcp.2010.03.002

Feldt, T., Metsäpelto, R.L., Kinnunen, U., \& Pulkkinen, L. (2007). Sense of coherence and five-factor approach to personality. European Psychologist, 12(3), 165-172. http://dx.doi.org/10.1027/1016-9040.12.3.165

Field, A. (2009). Discovering statistics using SPSS. (2nd edn.). London, United Kingdom: Sage Publications.

Galantino, M.L., Baime, M., Maguire, M., Szapary, P.O., \& Farrar J.T. (2005). Association of psychological and physiological measures of stress in health-care professionals during an 8-week mindfulness meditation program: Mindfulness in practice. Stress \& Health: Journal of the International Society for the Investigation of Stress, 21(4), 255-261. http://dx.doi.org/10.1002/smi.1062 
Germer, C.K. (2005). Mindfulness: What is it? What does it matter? In C.K. Germer, R.D. Diegel, \& P.R. Fulton (Eds.), Mindfulness and psychotherapy (pp. 3-27). New York, NY: Guilford Press.

Gibson, L.M., \& Cook, M.J. (1996). Neuroticism and sense of coherence. Psychological Reports, 79(1), 343-349. http://dx.doi.org/10.2466/pr0.1996.79.1.343

Giluk, T.L. (2009). Mindfulness, big five personality, and affect: A meta-analysis Personality and Individual Differences, 47(8), 805-811. http://dx.doi. org/10.1016/j.paid.2009.06.026

Goldberg, L.R. (1993). The structure of phenotypic personality traits. American Psychologist, 48, 26-34. http://dx.doi.org/10.1037/0003-066X.48.1.26

Goodwin, R.D., \& Friedman, H.S. (2006). Health status and the five-factor personality traitsPT in a nationally representative sample. Journal of Health Psychology, 11 643-654. http://dx.doi.org/10.1177/1359105306066610

Grossman, P., Niemann, L., Schmidt, S., \& Walach, H. (2004). Mindfulness-based stress reduction and health benefits a meta-analysis. Journal of Psychosomatic Research, 57, 35-43. http://dx.doi.org/10.1016/S0022-3999(03)00573-7

Hayes, S.C., Luoma, J.B., Bond, F.W., Masuda, A., \& Lillis, J. (2006). Acceptance and commitment therapy: Model, processes and outcomes. Behaviour Research and Therapy, 44, 1-25. http://dx.doi.org/10.1016/j.brat.2005.06.006

Herbst, L., Coetzee, S., \&Visser, D. (2007). Personality, sense of coherence and the coping of working mothers. SA Journal of Industrial Psychology, 33(3), 57-67. http://dx.doi.org/10.4102/sajip.v33i3.397

Hochwälder, J. (2012). The contribution of the big five personality factors to sense of coherence. Personality and Individual Differences, 53(5), 591-596. http://dx.doi. org/10.1016/j.paid.2012.05.008

Hyde, J.S. (2005). The gender similarities hypothesis. American Psychologist, 60(6), 581-592. http://dx.doi.org/10.1037/0003-066X.60.6.581

John, O.P., \& Srivastava, S. (1999). The big five trait taxonomy: History, measurement, and theoretical perspectives. Handbook of Personality: Theory and Research, 2 102-138.

Judge, T., \& Zapata, C. (2014). The person-situation debate revisited: Effect of situation strength and trait activation on the validity of the big five personality traits in predicting job performance. Academy of Management Journal, 57(4). http://dx. predicting job performance. Acader
doi.org/10.5465/amj.2010.0837

Kabat-Zinn, J. (2006). Mindfulness MI-based interventions in context: Past, presen and future. Clinical Psychology: Science and Practice, 10(2), 144-156. http://dx. doi.org/10.1093/clipsy.bpg016

Kardum, I., \& Hudek-Knezevic, J. (2012).The relationship between five-factor personality traits PT and specific health-related personality dimensions. International Journal of Clinical and Health Psychology, 12(3), 373-387.

Laher, S. (2010). Using exploratory factor analysis in personality research: Bestpractice recommendations: Original research. SA Journal of Industrial Psychology 36(1), 1-7. http://dx.doi.org/10.4102/sajip.v36i1.873

Laher, S., \& Croxford, S. (2013). Men are from Mars, women are from Venus: Exploring gender differences in personality in the South African context. SA Journal of Human Resource Management/SA TydskrifvirMenslikehulpbronbestuur, 11(1), Art.\#499. 8 pages. http://dx.doi.org/10.4102/sajhrm.v11i1.499

Latzman, R.D., \& Masuda, A. (2013). Examining mindfulness and psychological inflexibility within the framework of big five personality. Personality and Individual Differences, 55(2), 129-134. http://dx.doi.org/10.1016/j.paid.2013.02.019

Lindström, B. \& Eriksson, M. (2005). Salutogenesis. Journal of Epidemiology and Community Health, 59(6), 440-442. http://dx.doi.org/10.1136/jech.2005.034777

Louw, G.J., \& Viviers, A. (2010). An evaluation of a psychosocial stress and coping model in the police work context. SA Journal of Industrial Psychology, 36(1), 1-11. http://dx.doi.org/10.4102/sajip.v36i1.442

Louw, L., Mayer, C.-H., \& Baxter, J. (2012). Exploring relationship between value- and life-orientation and job satisfaction. Acta Commercii, 12, 45-67.

Louw, L., Mayer, C.-H., \& Surtee, S. (2014). Sense of coherence and mindfulness of women in leadership in higher education institutions. In A. Moses \& K. Stan (Eds.), Best paper proceedings of the 2nd Biennial Conference Africa Academy of Management, 8-11 January (pp. 138-153). Gaborone, Botswana: The University of Botswana.

Lawlor, M.S. (2014). Mindfulness in practice: Considerations for implications of mindfulness-based programming for adolescents in school contexts. New Directions in Youth Development, 142, 83-95. http://dx.doi.org/10.1002/ yd.20098

Macik-Frey, M., Quick, J.D., Quick, J.C., \& Nelson, D.L. (2009). Occupational health psychology: From preventive medicine to psychologically healthy workplaces. In A.G. Antoniou, C.L. Cooper, G.P. Chrousos, C.D. Spielberger, \& M.W. Eysenck (Eds.) Handbook of managerial behaviour and occupational health (pp. 3-19) Cheltenham, UK: Edward Elgar. http://dx.doi.org/10.4337/9781848447219.00008

Mama, A., (2003). Restore, reform but do not transform: The gender politics of higher education in Africa. JHEA/RESA, 1(1), 101-125.

Martin, P., \& Barnard, A. (2013). The experience of women in male-dominated occupations: A constructivist grounded theory inquiry. SA Journal of Industria Psychology, 39. Retrieved n.d., from http://sajip.co.za/index.php/sajip/article/ view/1099

Masuda, A., Price, M., \& Latzman, R.D. (2012). Mindfulness moderates the relationship between disordered eating cognitions and disordered eating behaviors in a nonclinical college sample. Journal of Psychopathology and Behavioral Assessment, 34, 107-115. http://dx.doi.org/10.1007/s10862-011-9252-7
Mayer, C.-H. (2011). The meaning of sense of coherence in transcultural management. Münster, Germany: Waxmann.

Mayer, C.-H., \& Van Zyl, L.E. (2013). Perspectives of female leaders on sense of coherence and mental health in an engineering environment. SA Journal of Industrial Psychology/SA TydskrifvirBedryfsielkunde, 39(2), Art.\#1097, 11 pages. http://dx.doi.org/10.4102/sajip.v39i2.1097 (27.06.2016).

McCrae, R.R., Terracciano, A., \& 78 Members from the members of the Personality Profiles of Cultures Project. (2005). Universal traits from the observer's perspective: Data from 50 cultures. Journal of Personality and Social Psychology 88, 547-561. http://dx.doi.org/10.1037/0022-3514.88.3.547

Mc Donald, K. (1998). Evolution, culture, and the five factor model. Journal of Cross-Cultural Psychology, 29, 119-149. http://dx.doi.org/10.1177/ 0022022198291007

Morgan, B., \& De Bruin, K. (2010). The relationship between the big five personality traits. PT and burnout in South African university students. South African Journal of Psychology, 40(2), 182-191. http://dx.doi.org/10.1177/ 008124631004000208

Morrison, I., \& Clift, S.M. (2006). Mental health promotion through supported further education: The value of Antonovsky's salutogenic model of health. Health Education, 106(5), 365-380. http://dx.doi.org/10.1108/09654280610685956

Mostert, K. (2009). The balance between work and home: The relationship between work and home demands and ill health of employed females. South African Journal of Industrial Psychology, 35(1). http://dx.doi.org/10.4102/sajip.v35i1.743

Muller, Y., \& Rothmann, S. (2009). Sense of coherence and employees' perceptions of helping and restraining factors in an organisation. SA Journal of Industrial Psychology/SA TydskrifvirBedryfsielkunde, 35(1), Art. \#731, 10 pages. http://dx. doi.org/10.4102/sajip.v35i1.731

Nunnally, J.C. (1978). Psychometric theory. New York: McGraw-Hill.

Opie, T., \& Henn, C.M. (2013). Work-family conflict and work engagement among mothers: Conscientiousness and neuroticism as moderators. SA Journal of Industrial Psychology, 39(1), 12 pages. http://dx.doi.org/10.4102/sajip.v39i1.1082

Powell, G.N., Butterfield, D.A. \& Parent, J.D. (2002). Gender and managerial stereotypes: Have the times changed? Journal of Management, 28(2), 177-193. http://dx.doi.org/10.1177/014920630202800203

Ramsay, L.J., Taylor, N., De Bruin, G.P. \& Meiring, D. (2005). The big five personality factors at work: A South African validation study. Poster presentation at the
International Symposium on Personality at Work 2005, May, Lueneburg, Germany.

Rothmann, S., \& Coetzer, E.P. (2002). The relationship between personality dimensions and job satisfaction. Management Dynamics: Journal of the Southern African Institute for Management Scientists, 11(1), 29-36.

Rothmann, S., \& Coetzer, E.P. (2003). The big five personality dimensions and job performance. SA Journal of Industrial Psychology, 29(1), 68-74. http://dx.doi. org/10.4102/sajip.v29i1.88

Salkind, N.J. (2012). Exploring research (8th edn.). Salt River, NJ: Pearson Publications.

Sauer, S., Walach, H., Offenbächer, M., Lynch, S., \& Kohls, N. (2011). Measuring mindfulness: A Rasch analysis of the Freiburger Mindfulness Inventory. Religions, 2, 693-706. http://dx.doi.org/10.3390/rel2040693

Schmidt, S. (2004). Mindfulness and healing intention: Concepts, practices, and research evaluation. The Journal of Alternative and Complementary Medicine, 10(1), 7-14. http://dx.doi.org/10.1089/1075553042245917

Steyn, H. S. (1999). Praktiesebetekenisvolheid: Die gebruik van effekgroottes [Practical significance: The use of effect sizes]. Wetenskaplikebydraes - Reeks B: Natuurwetenskappe Nr. 117. Potchefstroom: PU vir $\mathrm{CHO}$

Tabachnick, B.G., \& Fidell, L.S. (2001). Using multivariate statistics (4th edn.) Needham Heights, MA: Allyn \& Bacon.

Teferra, D. \& Altbach, P.G. (2004). African higher education: Challenges for the 21st century. Higher Education, 47, 21-50. http://dx.doi.org/10.1023/B:HIGH 0000009822.49980 .30

Van Schalkwyk, L., \& Rothmann, S. (2008). The validation of the orientation to life questionnaire in a chemical factory. SA Journal of Industrial Psychology, 34(2), 31-39. http://dx.doi.org/10.4102/sajip.v34i2.725

Van Zyl, L.E., \& Rothmann, S. (2012). Beyond smiling: The development and evaluation of a positive psychological intervention aimed at student happiness. Journal of Psychology in Africa, 22(3), 369-386.

Viernes Turner, C.S. (2002). Women of color in academe. Living with multiple marginality. The Journal of Higher Education, 73(1), 74-93. http://dx.doi. org/10.1353/jhe.2002.0013

Von Bothmer, M.I.K., \& Fridlund, B. (2003). Self-rated health among university students in relation to sense of coherence and other personality traits. Scandinavian Journal of Caring Science, 17, 347-357. http://dx.doi.org/10.1046/ j.0283-9318.2003.00234.x

Walach, H., Buchheld, N., Buttenmüller, V., Kleinknecht, N., \& Schmidt, S. (2006) Measuring mindfulness - The Freidburger Mindfulness Inventory (FMI). Personality and Individual Differences, 40, 1543-1555. http://dx.doi.org/10.1016/ j.paid.2005.11.025

Walsh, R., \& Shapiro, S.L. (2006). The meeting of meditative disciplines and Western psychology. A mutually enriching dialogue. American Psychologist, 61(3), 227-239. http://dx.doi.org/10.1037/0003-066X.61.3.227

Williams, J.E., Satterwhite, R.C., \& Best, D.L. (1999). Pan-cultural gender stereotypes revisited: The five factor model. Sex Roles, 40, 513-525. http://dx.doi. org/10.1023/A:1018831928829 